\title{
The Lexical Collocational Competence of Arab Undergraduate EFL Learners
}

\author{
Dina Abdel Salam El-Dakhs ${ }^{1}$ \\ ${ }^{1}$ English Department, Prince Sultan University, Riyadh, Saudi Arabia \\ Correspondence: Dina Abdel Salam El-Dakhs, College for Women, Prince Sultan University, Riyadh 11586, \\ Saudi Arabia. Tel: 966-55-271-3755.E-mail: dinadakhs@yahoo.com
}

Received: June 19, 2015 Accepted: July 6, 2015 Online Published: September 29, 2015

doi:10.5539/ijel.v5n5p60 URL: http://dx.doi.org/10.5539/ijel.v5n5p60

\begin{abstract}
Collocational competence largely contributes to vocabulary knowledge and hence to language proficiency. The present study examines the collocational competence of Arab undergraduate students who study English in a foreign language (EFL) environment. Focusing on lexical collocations, the study addresses four questions; (1) What is the learners' level of collocational competence?, (2) How does their collocational competence develop with increased language exposure?, (3) Does their collocational competence vary based on the word class of the collocates?, and (4) What are the types of collocational errors they produce? Using a specially designed test, the collocational competence of 90 Arab undergraduate learners at three academic levels in a private Saudi university was assessed. Findings showed that the collocational competence of learners was notably unsatisfactory despite the fact that English is the medium of instruction at the University. It was also found that collocational competence improves with increased language exposure but at a slow rate, and that learners were more confident in their use of verb + noun collocations than adjective + noun collocations. The study also revealed that learners produce more intralingual than interlingual errors of collocations. The findings are discussed in relation to the literature on collocational competence and pedagogical implications are presented.
\end{abstract}

Keywords: vocabulary knowledge, collocational competence, second language acquisition, English language teaching

\section{Introduction}

After long years of neglect in language teaching and learning, the acquisition of vocabulary attracted attention in the late 1970s and early 1980s, and the attention has been increasingly on the rise ever since. This came as a result of a relatively recent realization that vocabulary is a significant component in language learning and that "words are the building blocks of language and without them there is no language," (Milton, 2009, p. 3). Within the field of vocabulary, some aspects of word knowledge initially received greater attention than others. Following Nation's (2001) classification of word knowledge, it can be confidently stated that word form and word meaning attracted much more attention than word use in the early years of interest in vocabulary studies (Honde, 2009). Lately, however, more studies have shifted focus to the examination of word use, including the grammatical, lexical and stylistic constraints on the use of words in the linguistic context.

The present study examines the English language learners' knowledge of lexical constraints on word use by focusing on word combinations, an area that is very common in language discourse and distinguishes the speech of native than non-native speakers (Conklin \& Schmitt, 2007). More specifically, the study investigates the knowledge of Arab undergraduate learners of English collocations, which can be defined as "combinations of words which occur naturally with greater than random frequency" (Lewis, 1997, p. 44). The focus on the English language comes naturally since, similar to the global trend, English is the foreign language most taught and learned in the Arab World. The English language has also become the medium of instruction in diverse higher education institutions and a main requirement for employment or enrollment in graduate studies/ professional development programs. Hence, Arab undergraduate learners are now required to achieve a high degree of English language competence and to be able to use the language both accurately and fluently to achieve a reasonable standard of living. 


\section{Statement of Research Problem}

The examination of Arab learners' collocational competence in English comes as a result of the researcher's personal observation that a large number of Arab learners struggle with this area of vocabulary knowledge. Over more than 20 years of teaching English to Arab learners from different nationalities, the researcher has frequently noted the learners' inability to produce correct word combinations that sound native-like. So often, learners would produce combinations that sound extremely awkward in English (e.g., "introduce apology" instead of "offer apology"), struggle to express their message in a precise and concise manner and avoid using certain lexical and grammatical patterns due to lack of knowledge of appropriate collocates. This personal observation has also been recently reported in the literature (please, refer to section 5. Literature Review) and triggered increasing attention.

The Arab learners' struggle with word combinations is partially due to the arbitrary nature of these combinations. Farrokh (2012), for example, notes the absence of any logic why good chance, high probability and strong likelihood are acceptable collocations in English while strong chance, good probability and high likelihood are not. Similar observations were made by Sinclair (1991) that we break rules but not break regulations, hold a funeral but not hold a burial, make an attempt but not have an attempt and have a try but not make a try. However, the arbitrary nature of collocations cannot be the sole cause of this serious difficulty.

The present study is an attempt to investigate the Arab learners' knowledge of English collocations with the purpose of shedding light on this significant area of language learning that hinders learners' communication. The paper aims to achieve four goals; (1) assess the learners' productive knowledge of collocations, (2) examine the influence of increased language exposure on the acquisition of collocations, (3) study the effect of word class on the acquisition of collocations and (4) identify common error types and their potential causes. Addressing these areas of collocational knowledge should help better understand the situation under scrutiny and, hence, propose solutions that could support learners along the path of language learning.

\section{Importance of the Study}

This study is partially important due to the significance of collocational competence itself. Nation (2001) summarizes this significance by stating that "all fluent and appropriate language requires collocational knowledge," (p. 318). According to El-Dakhs (2015), collocational competence is a key component of second language learning for a variety of reasons. One reason is their high frequency of occurrence in discourse, estimated at $70 \%$ of everything we say, hear, read, or write (Hill, 2000). Another is their facilitatory effect to language processing. Mastering frequent collocations as pre-fabricated chunks facilitates both language comprehension and production. Collocations also contribute to understanding word meaning. For example, the meaning of the word "heavy" varies based on its collocates in "heavy meal," "heavy smoker," "heavy traffic," and "heavy man." Besides, learning collocations as ready-made chunks is necessary since most collocations are arbitrary. There is no clear justification why we "make" mistakes but "do" homework. Further explanation of the importance of collocations can be found in Alsulayyi, 2015; El-Dakhs, 2015; Miqdad, 2012; Alsakran, 2011.

In addition to the importance of collocational competence, the present study also gains significance from its goals and design. The study contributes to our understanding of the processes involved in the production of collocations, which has proved much more difficult than their comprehension. The study particularly sheds the light on the influence of relevant factors including the effect of increased language exposure and the effect of word class on the acquisition of collocations. Analyzing the participants' errors will also help understand the types of common collocational errors among this population and their potential causes. Besides, the current study focuses on Arab learners at the undergraduate level, providing an assessment of the participants' collocational competence in addition to an analysis of production difficulties. Hence, the results of the study could prove useful to educational institutions in the Arab World.

\section{Theoretical Background}

The term "collocation" has received diverse definitions along the history. One of the earliest is Firth's (1957) "the company that words keep," (p. 183). More recent definitions include Cruse's (1986) "sequences of lexical items, which habitually co-occur," (p. 40), McCarthy's (1990) "a marriage contract between words," (p. 12) and Woolard's (2000) "the co-occurrence of words which are statistically much more likely to appear together than random chance suggests," (p. 29). In simple words, collocations refer to a language-specific phenomenon in which two or more words frequently occur together. That is, some word combinations are acceptable (e.g., strong tea) while others are not (e.g., powerful tea). 
Two classifications of collocations are relevant to the present study. The first classification is Benson, Benson \& Illson's (1986) classification into grammatical collocations and lexical collocations. According to them, grammatical collocations consist of an open class word in addition to a preposition, an infinitive or a clause (e.g., noun + preposition, noun + to infinitive $\&$ adjective + that clause). As for lexical collocations, they include open class words (e.g., verb + noun, adverb + adjective and adverb + verb). The present study examines the learners' knowledge of lexical collocations, particularly the "verb + noun" collocations and the "adjective + noun" collocations, which are two among the most frequent collocational patterns in English.

A second relevant classification is categorizing collocations according to their predictability of occurrence. Collocations vary along a continuum in this regard, a finding that was represented in various classifications (e.g., Howarth, 1998; Hill, 2000; Lewis, 2000). For instance, Hill (2000) classifies collocations as follows:

1. Unique collocations

These are fixed collocations in the sense that collocates cannot be replaced by other words (e.g., foot the bill).

\section{Strong collocations}

These are less fixed than unique collocations. Few words can replace the target collocates (e.g., move to tears).

\section{Medium-strength collocations}

These are words that frequently go together. Learners may know the individual words, but not the word combinations (e.g., hold a conversation).

\section{Weak collocations}

These are easily predictable combinations that should cause no real difficulty for learners (e.g., green shirt).

The present study does not examine weak collocations as they should cause no special difficulty for learners. Most collocations in the study tests are strong or of medium strength since they are difficult to predict and are much more frequent than unique collocations.

Recent studies have highlighted a number of factors that could influence the learner's production of collocations. One likely factor is the learner's mother tongue (e.g., Miqdad, 2012). This is most obvious when collocations in the learner's native language are incongruent with the target language, resulting in deviant productions. Intralingual factors could also be influential (e.g., Ridha \& Al-Riyahi, 2011). For example, learners may produce a wrong collocate due to its large number of synonyms. The more synonyms an item has, the more difficult it is to produce a restricted collocation (Abu Baba's, 2012). A third factor is the learning environment (e.g., Alsulayyi, 2015). A number of recent studies, for instance, have highlighted that learning the language in a second language environment facilitates the production of collocations more than learning in a foreign language context. The present study examines two other factors; i.e., the increased language exposure and the word class of the collocates. More factors may emerge as a result of analyzing the participants' errors.

The analysis of participants' errors falls under the approach "error analysis," which has been in practice in linguistic circles for decades. Norrish (1994) distinguishes between two approaches to error analysis. The first is to set up categories of errors based on the researcher's preconceptions of the learners' performance, and then for the researcher to classify the errors under these categories. This approach is relatively fast to apply and will conform with prior expectations by the researcher based on his/her experience and investigation of the literature. However, the pre-judgment of errors before actual examination may not really lead to an accurate description. The second approach to error analysis is to classify errors into categories after their examination. Some unexpected categories may emerge, but this will provide an accurate description of the learners' performance. The present study follows the second approach. Erroneous collocates are identified and then categories emerge. It is noted though that the two broad categories of interlingual and intralingual errors will be observed.

\section{Literature Review}

The last two decades have witnessed a growing interest in examining the collocational knowledge of English language learners in various parts of the world. Studies targeted learners with varied linguistic backgrounds, including Iran (e.g., Torabian, Maros \& Subakir, 2014), Hong Kong (e.g., Fan, 2009), Thailand (e.g., Phoocharoensil, 2014), Spain (e.g., Jaén, 2007), Taiwan (Li, 2005), Turkey (e.g., Bağci, 2014), Malaysia (e.g., Yunus \& Awab, 2011) and Russia (e.g., Siyanova \& Schmitt, 2008). The present survey of literature will, however, shed light on the studies conducted in the Arab World since the current study examines the collocational competence of Arab undergraduate learners of English. 
Similar to the global trend, interest in examining the collocational knowledge of Arabic-speaking learners of English has increased, particularly over the last decade. A major focus for these studies was to assess the collocational knowledge of learners from both the receptive and productive aspects. Two relevant studies are Brashi (2009) and Miqdad (2012). Both studies examined the collocational knowledge of undergraduate university students majoring in English in Saudi Arabia (Brashi, 2009) and in Palestine (Miqdad, 2012). Using multiple-choice tests and blank-filling tests, the researchers investigated the participants' receptive and productive knowledge of lexical collocations, namely; verb + noun collocations (Brashi, 2009) and verb + noun collocations and adjective + noun collocations (Miqdad, 2012). The results in both studies revealed that the participants' collocational knowledge was inadequate. It was also noted that the participants' receptive knowledge was far better than their productive knowledge and that the first language influence constituted a major hindrance, among others, to the participants' completion of the study tasks.

In the same vein came the studies of Shehata (2008) and Alsakran (2011). In addition to examining the receptive and productive collocational knowledge of advanced Arab learners, the two studies also investigated the influence of the language environment (i.e., learning English as a second language (ESL) versus as a foreign language (EFL)) on the acquisition of collocations and compared the acquisition of different types of lexical collocations (e.g., verb + noun \& adjective + noun). The EFL participants came from Cairo, Egypt (Shehata, 2008) and Riyadh, Saudi Arabia (Alsakran, 2011). The ESL participants came from diverse Arab nationalities who were enrolled in different programs at American universities. Using gap-filling tests and appropriateness judgment tests, the two studies showed the poor collocational knowledge of Arab learners despite their relatively high language proficiency. The studies also revealed that (1) the learners' receptive collocational knowledge is superior to their productive knowledge, (2) learning English in a second language environment better supports the acquisition of collocations than learning English in a foreign language context and (3) learners may demonstrate varied levels of collocational competence in accordance to the target types of lexical collocations (e.g., learners found it easier to master verb + noun collocations than adjective + noun or verb + preposition collocations).

Interestingly, the observed poor collocational knowledge of Arabic-speaking English language learners was also proved among Master's Degree students majoring in English language, who had completed their Bachelor's Degrees at English Language Departments. Two illustrative studies are Abu Naba'h (2012) and Shammas (2013). The two studies targeted Master's Degree students majoring in English language, whether for teaching (Abu Naba'h, 2012) or for translation (Shammas, 2013). The participants, who came from Jordan, Algeria, Syria and Lebanon, were hence expected to possess an advanced English language competence. The results of the two studies, however, came unsatisfactory and clearly highlighted the participants' insufficient knowledge of English collocations. It was also noted that the participants largely rely on a first language transfer strategy while attacking unknown collocations, which mostly led to deviant productions. The two studies concluded that collocational knowledge may lag far behind the general lexical competence of second language learners. They also pointed out that a learner's ability to understand collocations in the second language does not ensure efficient use of collocations in language production.

The recurrent finding that productive collocational knowledge lags far behind the receptive knowledge has stimulated a number of studies, including the present one, to solely focus their investigation on the production of collocations. Such studies have adopted two methodologies; using specially designed production tests or analyzing the written production of learners. For instance, Noor \& Adubaib (2011) examined the strategies used in producing English lexical collocations by 88 Saudi university students majoring in English. Based on a standardized proficiency test, the participants were classified into higher proficiency and lower proficiency. Both groups completed two written elicitation tasks, filled out a self-checklist and participated in an interview. In terms of the participants' collocational competence, the results came unfavorable as the average of acceptable collocations stood at $30.75 \%$ (43.2\% for the participants of higher proficiency and $18.3 \%$ for those with lower proficiency). As for the strategies employed in the production of collocations, a taxonomy was devised including retrieval strategies, reduction strategies, test-taking strategies, first language strategies and second language strategies. It was noted that participants relied on second language based strategies more often than all other strategies. This highlighted the influence of intralingual factors in the production of collocations. It was also noted that high-proficient learners seem to employ strategies significantly different than low-proficient learners.

Other studies relied on the analysis of students' writing. A case in point is Abdul Ridha \& Al-Riyahi (2011) who investigated the lexical collocational errors in the writings of Iraqi EFL learners. The participants consisted of 40 third-year university students majoring in English at the College of Education, University of Basrah. The study relied on analyzing over 100 essays submitted by the participants as homework assignments. The results of the 
study showed that the participants' knowledge of lexical collocations is generally inadequate. A strong tendency to avoid the use of certain types of lexical collocations (e.g., adverb + adjective, verb + adverb and noun + noun) was observed. It was noted that students could not express themselves concisely or precisely due to their lack of knowledge of these collocations. As for other types of collocations, most errors were found with the patterns verb + noun $(33.76 \%)$, adjective + noun $(24.84 \%)$ and noun + verb (22.29\%). Regarding the causes of errors, the strategy of negative transfer came top of the list $(36.31 \%)$ followed by other intralingual strategies, such as hypothesizing false concepts (31.21\%) and approximation (14.65\%).

Likewise, Alsulayyi (2015) analyzed the participants' essays to examine their production of collocations, but his study focused on grammatical collocations. Examining the writing of 10 Saudi undergraduate students majoring in English, Alsulayyi (2015) found out that the learners studying in the United Kingdom produced fewer grammatical collocation errors than those studying in Saudi Arabia despite their similar IELTS score ranging between 5.5 and 6. This lent further support to Shehata's (2008) and Alsakran's (2011) finding that the language environment (ESL versus EFL) influences the acquisition of collocations. Further examination of the participants' writing highlighted their tendency to avoid certain grammatical patterns which may go beyond their English proficiency level, such as the "adjective + that clause" and the "noun + that clause". As for the patterns they produce, the highest number of errors was observed among two patterns; i.e., "noun+ preposition" and "adjective + preposition", and a main cause for these errors was the influence of first language on the choice of prepositions.

The present study represents another contribution to the studies examining the Arab learners' production of lexical collocations. In addition to assessing the learners' efficient use of collocations, the study examines three important aspects; (1) the influence of increased language exposure on the acquisition of collocations, (2) the effect of the part of speech of collocates on the acquisition of collocations, and (3) the common types of production errors and possible causes.

\section{Research Questions}

The current study addresses four questions with relevance to Arab undergraduate EFL learners:

1) What is their level of productive collocational competence?

2) What is the effect of increased language exposure on the acquisition of collocations?

3) What is the effect of word class on the acquisition of collocations?

4) What are the types of collocational errors produced by the learners?

\section{Methodology}

\subsection{Participants}

The participants of the study constituted of 90 undergraduate Arab students studying at a private Saudi university where English is the medium of instruction. The participants were recruited from three stages of university education; 30 participants from the preparatory year program, 30 participants from the second-year of university education and 30 students from the fourth year of university education. All the participants were female, Arab learners ranging in age between 17 and 25 . The sample can be classified as follows:

\begin{tabular}{|c|c|c|c|}
\hline Preparatory Year & Second Year & Fourth Year & Total \\
\hline 30 & 30 & 30 & 90 \\
\hline
\end{tabular}

Upon applying to Saudi universities, students sit an admission test that assesses their English language competence among other skills (e.g., computer skills and mathematical knowledge). At the Saudi University where the present study took place, students can skip the Preparatory Year Program and join the university program directly upon scoring 6 on their IELTS test or an equivalent score on TOEFL. Students achieving lower than this score on these international tests sit an institutional placement test that classifies them into three levels; beginners, elementary and pre-intermediate. The beginners study English for three academic semesters, the elementary study for two semesters and the pre-intermediate study for one semester prior to joining the university programs of their choice. The preparatory year students in the present study were recruited from among the pre-intermediate group.

The remaining students in the study represent higher levels of language exposure since English is the medium of instruction for their educational programs. Although English language classes are taught at the preparatory year program to enhance students' language competence and prepare them for the linguistic demands of university 
education, the second and fourth year students are exposed to English as part of their academic courses (i.e., content-based instruction). Hence, the higher the academic semester they are enrolled in, the higher the English language exposure they have experienced. It is worth noting here that the second and fourth year students in the present study were recruited from the Departments of Business Administration, Computer \& Information Sciences and Architecture. This choice was purposeful to avoid departments that may show exceptional mastery the English language (e.g., English Department) or lower exposure of the English language due to studying some university courses in Arabic (e.g., Law Department).

It is worth noting that it was verified that the participants had not lived in an English-speaking country prior to taking the study tests. It has also been noted that neither of their parents speaks English as a native language.

\subsection{Procedure}

The study assessed the students' productive knowledge of English collocations through one gap-fill and translation test consisting of two exercises (See Appendix A). The first exercise consisted of 15 sentences, each of which with a missing verb. The participants were required to fill in the missing verb per sentence relying on their understanding of the sentence in addition to an Arabic equivalent provided for the missing verb. The second exercise also consisted of 15 sentences, each with a missing adjective. Similar to the first exercise, the participants had to write the missing adjectives based on their understanding of the English sentences and the provided Arabic equivalents of the adjectives.

The test design took a number of factors into consideration. First, the majority of words employed in the test belong to the General Service List (=the list constituting the most frequent 2,000 words in the English language). The few words that do not fall in this category are judged as frequently used words in the study setting (e.g., assignment, chairperson, dean, Saudi and exam). This can be verified using an online vocabulary profiler (e.g., The University of Hong Kong's Profiler). Besides, the English sentences were reviewed by 5 English language instructors at the Preparatory Year Program who confirmed that the sentences can be understood by the participants. Second, the Arabic words which were provided as translation equivalents for the missing words belong to standard Arabic. Since the study was applied to university students of diverse Arab nationalities, it was important to avoid using any dialect-specific equivalents, particularly with the diglossic nature of the Arabic language which can render dialect-specific vocabulary incomprehensible to speakers of other dialects.

In addition to the abovementioned factors, two other factors were taken into consideration in relation to test administration. On the one hand, the researcher highlighted to the participants that supplying the missing words based on the sole translation of the Arabic equivalents will result in erroneous productions. Examples were provided on the board and discussed with the participants. For instance, the Arabic word يصبخ can be translated as "paint" or "dye." The participants were shown that only "dye" will be correct in the sentence "Try to dye your hair." Hence, the participants were well-informed of the need to supply the missing words based on the joint understanding of sentences and the Arabic equivalents. On the other hand, the researcher did not wish for time constraints to interfere with the participants' performance. Thus, the participants were told to complete the tasks at their own pace. The participants took 20-40 minutes to complete the task. Meanwhile, they were not allowed to consult any references or discuss their answers with colleagues. They were, however, allowed to direct questions to the researcher who provided any necessary explanation.

\section{Results}

The results section is classified in accordance with the research questions.

\subsection{Research Question (1)}

\section{What is the level of productive collocational competence of Arab undergraduate EFL learners?}

The participants' answers were marked to assess whether they were acceptable collocates of the head nouns and matched the Arabic equivalents provided. Erroneous spelling or inflections were disregarded as long as the pronunciation of words was clear. Only the words that matched the meaning of the Arabic equivalents were considered. Most often, it was clear whether the collocations were acceptable. However, in case of doubt, the acceptability of the collocations was judged against Oxford Collocations Dictionary for Students of English, The Corpus of Contemporary American English and native speakers' judgments. The results were categorized per the participants' academic status (i.e., preparatory year, second year or fourth year) and per the word class of the missing collocates (i.e., verbs or adjectives). Table 1 and Figure 1 show a summary of the results. 
Table 1. Results of the collocation test per academic year

\begin{tabular}{|c|c|c|c|c|c|c|}
\hline \multirow[b]{2}{*}{ Tests } & \multicolumn{2}{|c|}{ Preparatory year } & \multicolumn{2}{|c|}{ Second year } & \multicolumn{2}{|c|}{ Fourth year } \\
\hline & Mean & Std. Dev & Mean & Std. Dev & Mean & Std. Dev \\
\hline Verb collocations & 44.2 & 14.9 & 49.8 & 20.6 & 56.9 & 18.7 \\
\hline Adjective collocations & 28.0 & 14.3 & 47.6 & 20.6 & 50.4 & 23.3 \\
\hline
\end{tabular}

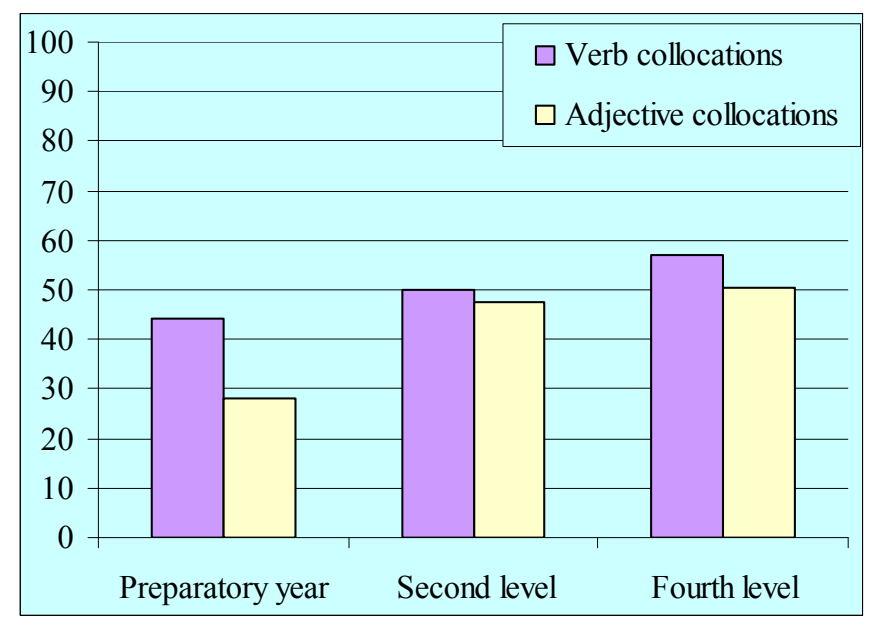

Figure 1. Results of the collocations test per academic year

As shown above, the test results reflect the participants' poor command of English collocations as the highest percentages for acceptable collocations, scored by the fourth year participants, stood at $56.9 \%$ for verb collocations and at $50.4 \%$ for adjective collocations. Lower percentages were noted for the preparatory and second years. The preparatory year scored $44.2 \%$ for verbs and $28 \%$ for adjectives whereas the second year scored $49.8 \%$ for verbs and $47.6 \%$ for adjectives.

\subsection{Research Question (2)}

\section{What is the effect of increased language exposure on the acquisition of collocations?}

The results were analyzed using one way analysis of variance (F-test) to assess the difference in the production of acceptable collocations among the participants' years of study. The analysis showed statistical significance at 0.05 for verb collocations and at 0.01 for adjective collocations. Applying the Tukey test, a multiple range test, it was found that the difference for verb collocations is only statistically significant between the preparatory year and the fourth year in favor of the latter. As for the adjective collocations, statistical significance was noted at two levels; (1) between the preparatory year and the second year in favor of the second year, and (2) between the preparatory year and the fourth year in favor of the fourth year. Table 2 and Figure 2 show a summary of the results.

Table 2. F-Test results for the differences per academic year

\begin{tabular}{lllllll}
\hline Tests & Source & Sum of Squares & df & Mean Square & F & Sig. \\
\hline \multirow{2}{*}{ Verb collocations } & Between Groups & 2418.77 & 2 & 1209.38 & \multirow{2}{*}{3.64} & 0.030 \\
& Within Groups & 28884.44 & 87 & 332.01 & & $(0.05)$ \\
Adjective collocations & Between Groups & 8945.19 & 2 & 4472.59 & 11.47 & 0.000 \\
& Within Groups & 33939.26 & 87 & 390.11 & & $(0.01)$ \\
\hline
\end{tabular}




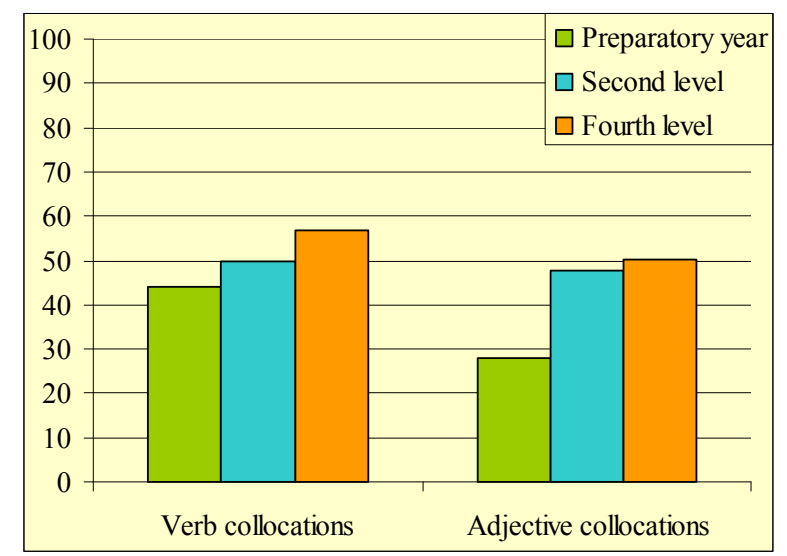

Figure 2. Comparison of the results per academic year

\subsection{Research Question (3)}

What is the effect of word class on the acquisition of collocations?

The test results were analyzed using the T-test to assess the difference between verb collocations and adjective collocations. The results of the comparison are shown in Table 3 and Figure 3 below. As shown in Table 3, the results were statistically significant for the preparatory year and the fourth year in favor of the verb collocations. No statistical significance was, however, identified for the second year. Overall, scores for the verb collocations are significantly higher than the adjective collocations.

Table 3. T-test results comparing verb collocations and adjective collocations

\begin{tabular}{llllll}
\hline Study level & Tests & Mean & Std. Deviation & T-value & Sig. \\
\hline Preparatory Year & Verb collocations & 44.22 & 14.91 & 7.27 & 0.000 \\
& Adjective collocations & 28.00 & 14.27 & & $(0.01)$ \\
Second Year & Verb collocations & 49.78 & 20.62 & 0.78 & 0.444 \\
& Adjective collocations & 47.56 & 20.62 & & (N. S.) \\
Fourth Year & Verb collocations & 56.89 & 18.67 & 2.81 & 0.009 \\
All level & Adjective collocations & 50.44 & 23.27 & & $(0.01)$ \\
(all sample) & Verb collocations & 50.30 & 18.75 & 5.37 & 0.000 \\
\hline
\end{tabular}

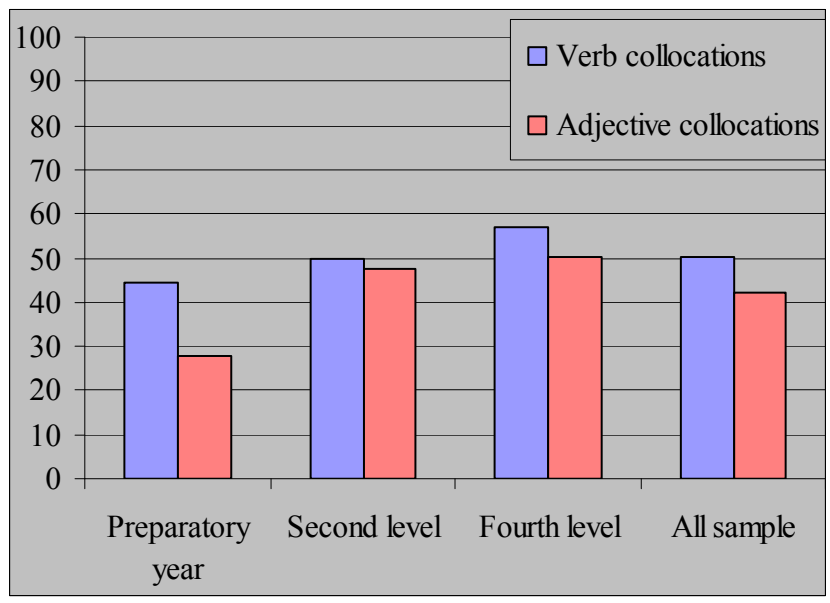

Figure 3. Comparison of the results per type of collocation 


\subsection{Research Question (4)}

What are the types of collocational errors produced by the participants?

The participants produced a total of 1280 incorrect answers. These incorrect answers were classified into 7 categories. The first two were the provision of no response (included in Table 4 as blank) or of more than one word. Both were considered wrong answers since the instructions were to produce only one word. The remaining answers fell under 5 categories as follows:

\section{Second Language (L2) Synonym}

The target collocate was replaced with an English synonym. For example, "civil" in "civil war" was replaced with "national", or "comprehensive" in "comprehensive exam" with "complete".

\section{Another Meaning}

The target collocate was replaced with another word that is not an equivalent of the Arabic word provided. Most often, however, the replacement is a frequent collocate of the head noun. For example, the word "vague" in "vague promises" has been replaced with "fake." Similarly, the word "promising" in "promising student" was replaced with "smart."

\section{First Language (L1) Transfer}

The collocate supplied shows clear influence of the first language. This is most evident, for instance, in replacing "civil war" with "private or family war" or replacing "absolute power" with "divorced power".

\section{Word Class}

The target collocate was replaced with a word similar in meaning but that belongs to another word class. For instance, "sudden pain" was supplied as "surprise pain" and "shiny hair" with "glitter hair."

Formal Similarity

The erroneous replacement is similar to the correct collocate in form, whether phonologically or morphologically. For example, "freckled" in "freckled face" was replaced with "pickled" and "catch" in "catch fish" with "cash."

As shown in Table 4 below, after excluding the blank answers and the answers consisting of more than one word, the highest type of erroneous collocates across all academic years was the use of an English synonym (an average of 33\%). This was followed with supplying a word with another meaning that is often a collocate of the head noun (an average of 17\%). As for the other three types, L1 transfer, word class and formal similarity, they stood at notably low percentages. The highest percentage was only $8 \%$ for the use of words with another word class among the Preparatory Year learners.

Table 4. Classification of collocation errors

\begin{tabular}{llllllll}
\hline Academic Year & Blank & $\begin{array}{l}\text { More than } \\
\text { one word }\end{array}$ & $\begin{array}{l}\text { L2 } \\
\text { Synonym }\end{array}$ & $\begin{array}{l}\text { Another } \\
\text { meaning }\end{array}$ & $\begin{array}{l}\text { L1 } \\
\text { transfer }\end{array}$ & $\begin{array}{l}\text { Word } \\
\text { Class }\end{array}$ & Formal similarity \\
\hline Preparatory Year & $34 \%$ & $1 \%$ & $30 \%$ & $14 \%$ & $6 \%$ & $8 \%$ & $7 \%$ \\
Second Year & $45 \%$ & $3 \%$ & $28 \%$ & $13 \%$ & $2 \%$ & $4 \%$ & $5 \%$ \\
Fourth Year & $20 \%$ & $3 \%$ & $42 \%$ & $23 \%$ & $4 \%$ & $2 \%$ & $6 \%$ \\
\hline
\end{tabular}

\section{Discussion}

The first goal of the present study was to assess the productive collocational knowledge of Arab undergraduate EFL learners. The participants came from different Arab nationalities, academic departments and university years. They were recruited from a private Saudi university where English is the medium of instruction, a factor that should support the participants' vocabulary knowledge. The results, however, highlight the inadequate productive collocational knowledge of the participants, a finding in line with a number of earlier studies on the collocational competence of Arab EFL learners (e.g., Brashi, 2009; Noor \& Adubaib, 2011; Miqdad, 2012). The scores of the participants were so notably low that only the fourth year participants barely managed to score more than $50 \%$ (56.9\% for verb collocations and 50.4\% for adjective collocations). The fact that scoring 6 on IELTS tests is a requirement to skip the Preparatory Year at the Saudi University and the fact that students cope with the demands of university education in English highlight that high proficiency in a second language may not entail high command of collocational competence. This also shows that the comprehension of collocations may not lead to mastering their production in natural language use. 
The second goal of the study was to examine the influence of increased language exposure on the participants' collocational competence. Within a university setting where English is the medium of instruction, does the increased language exposure across the study years support the acquisition of collocational competence? The results show that the increased language exposure may support the acquisition of collocational knowledge but at a slow rate. For example, statistical significance in the production of verb + noun collocations was only noted between the preparatory year and the fourth year of university education. The difference in the mean score was only $12.7 \%$. As for the adjective + noun collocations, statistical significance was observed between the preparatory year and the second year and between the preparatory year and the fourth year, but no statistical difference was observed between the second year and the fourth year. The mean scores were $28 \%$ for preparatory year, $47.6 \%$ for second year and $50.4 \%$ for fourth year. Hence, collocational competence is an area that may require explicit instruction or form-focused instruction to develop with a faster pace.

The third goal of the study was to investigate the effect of the word class of collocates on the acquisition of the collocations. The findings reveal that the word class of collocates may influence their acquisition. The participants seemed in better command of verb + noun collocations than adjective + noun collocations, particularly at the preparatory and fourth years. This may be interpreted in terms of the prime significance of verbs. English sentences must consist of main verbs, but may not include adjectives. University students, however, need to master adjectives as well to produce acceptable academic writing. Hence, their knowledge of adjective + noun collocations almost doubles over the study years. This finding calls for further examination of collocations to discover the types that are most problematic for Arab learners. Miqdad (2012) had similarly pointed out that verb+ noun collocations were easier for Arab learners than adjective + noun collocations and verb + preposition collocations. Besides, Abdul Ridha \& Al-Riyahi (2011) had highlighted the participants' tendency to avoid certain types of lexical collocations, such as adverb + adjective and verb + adverb.

The fourth and final goal of the study was to explore the common types of collocational errors produced by the participants. Earlier studies in this regard led to contradictory findings with some studies (e.g., Abdul Ridha \& Al-Riyahi, 2011; Brashi, 2009) demonstrating a major influence for the first language on the production of unacceptable collocations and other studies (e.g., Noor \& Adubaib, 2011) revealing a stronger influence for second language based strategies. The present study has revealed a major influence for intralingual errors in the production of collocations. The highest number of unacceptable collocations produced by the participants was the replacement of target collocates with English synonyms. This was followed with the replacement of the correct collocates with other collocates of the head nouns that have a different meaning. The two types of errors accounted in average for $50 \%$ of the incorrect answers. The other types of collocational errors (i.e. L1 transfer, another word class and a word of formal similarity to the target collocate) stood at very low scores ranging between a maximum of $8 \%$ and a minimum of $2 \%$.

These findings can be interpreted in relation to the language proficiency level of the participants and their learning environment. It seems that the relatively high-proficiency level of the participants has led to stronger mental connections among their second language words more than among their first and second language words. This is a well-known development in the bilingual mental lexicon. With increased proficiency, connections among second language words and their first language equivalents are weakened while the connections among second language words that share linguistic similarity are strengthened. Hence, the participants adopted more second language based strategies than first language strategies in their production. This may have been further supported by the learning environment where English is the medium of instruction and also a dominant medium for communication with the multinational community on campus.

The results also show that the learners' vocabulary is expanded in terms of breath, but not depth. In other words, the participants have acquired a large number of English words that share semantic similarity, but have not acquired the lexical restrictions on the use of these words. Hence, they use most synonyms interchangeably, unaware of their inappropriate uses in particular contexts. Notably, the fourth year participants scored the highest rate of using synonyms interchangeably $(42 \%)$, which again shows that they are acquiring more and more words without learning the restrictions on their use. In addition to synonyms, it seems that the participants acquire less frequent words before properly mastering the frequent ones which may prove more valuable for communication. For example, the participants produced words like "hook" and "hunt" for fish but missed the much more frequent word "catch." Similarly, a great deal of participants could not supply the frequent verb "make" in the collocation "make the bed." 


\section{Limitations}

The present study examined the lexical collocational competence for Arab EFL learners. Despite the fact that the learners belonged to different Arab nationalities, they were mostly graduates of the Saudi schooling system. It would have been interesting if the participants were actually recruited from various universities in the Arab World where students have graduated from different schooling systems. The present study was also implemented only on female learners. It would be interesting to implement the study on both male and female learners in the future to avoid any potential effects of gender on the results. Finally, the results of the study must be interpreted in the light of the test specially designed for the study. Different results may be observed in the natural production of collocations during speaking or writing.

\section{Conclusion}

The present study has shed the light on the inadequate productive knowledge of collocations among Arab undergraduate EFL learners. The study particularly focused on the acquisition of lexical collocations represented by two patterns; (1) verb + noun collocations and (2) adjective + noun collocations. The study has also revealed a positive, yet limited, influence of increased language exposure on the acquisition of collocations. This was somehow surprising since English is the medium of instruction for the study participants. That is, the participants study their subject matter courses completely in English. It was also surprising because a large number of the university professors are non-Arabic speaking and are native or near-native speakers of English. Thus, most student-professor interaction, inside or outside the classroom, is conducted in English. These findings highlight the need for the intervention of form-focused instruction to enhance the participants' focus on word combinations and increase their collocational competence.

The present study also explored the influence of word class on the acquisition of collocations. Comparing the acquisition of verb + noun collocations with adjective + noun collocations, it was found that the participants showed less command of the latter. This may be interpreted in terms of the fact that verbs occupy a more central position in the sentence than adjectives. This finding calls for more research in the area of collocational competence to discover the lexical patterns that cause difficulty for language learners. Discovering these patterns can support learners better in their language learning journey.

A final important finding of the study is the dominance of intralingual errors in the production of unacceptable collocations. The participants seemed to know a large number of words, but their knowledge is insufficient to handle collocational restrictions. The participants would use synonyms interchangeably resulting in deviant collocational productions. Most interestingly, the fourth year participants adopted this strategy the most, showing that their lexical repertoire may be large but not reflecting depth of vocabulary knowledge. Interlingual errors, however, came at the periphery as they stood at a maximum of $6 \%$ for the preparatory year learners. The participants, mainly of intermediate level or above, seem to have overcome the negative influence of their first language in producing collocations, but show struggle with intralingual challenges.

\section{Pedagogical Implications}

Based on the findings of the present study, some pedagogical implications can be listed below:

1) Teaching vocabulary on the sole basis of individual words does not support efficient language use. Learners need to acquire frequent word combinations as pre-fabricated, ready-made chunks to enhance their language use.

2) Increased language exposure may not suffice for the development of adequate colloctional knowledge. It seems that learners may not "notice" (Schmidt, 1990) the collocational restrictions alone, and will, thus, require the intervention of form-focused instruction.

3) In EFL contexts, Content-Based Instruction needs to be supplemented with a focus on linguistic accuracy. Learners' fluent use of language to express their ideas may not lead to improving their accurate command of the language.

4) It is important to raise learners' awareness of the restrictions of use on synonyms. Learners, at relatively high proficiency levels, seem to lack adequate knowledge to use synonyms appropriately.

5) Increased vocabulary knowledge does not only mean learning a larger number of words or mastering infrequent words. An important aspect of lexical competence is enhanced breadth of vocabulary knowledge, particularly for highly frequent words. It is important to study the different uses of frequent words as they account for a large percentage of discourse. 


\section{References}

Abdul Ridha, N. S., \& Al-Riyahi, A. A. (2011). Lexical collocational errors in the writings of Iraqi EFL learners. Journal of the College of Arts, University of Basrah, 58, 24-51.

Abu Naba'h, A. M. (2012). An investigation of the English collocational knowledge of Jordanian graduate students. Damascus University Journal, 28(2), 37-61.

Alsakran, R. A. (2011). The productive and receptive knowledge of collocations by advanced Arabic-speaking ESL/EFL learners. Unpublished MA dissertation, Colorado State University, USA. Retrieved from http://digitool.library.colostate.edu/exlibris/dtl/d3_1/apache_media/L2V4bGlicmlzL2R0bC9kM18xL2FwY WNoZV9tZWRpYS8xMjI4NTI=.pdf

Alsulayyi, M. N. (2015). The use of grammatical collocations by advanced Saudi EFL learners in the UK and KSA. International Journal of English Linguistics, 5(1), 32-43. http://dx.doi.org/10.5539/ijel.v5n1p32

Bağci, N. (2014). Turkish university level EFL learners' collocational knowledge at receptive and productive levels. Unpublished MA dissertation, Middle East Technical University, Turkey. Retrieved from http://etd.lib.metu.edu.tr/upload/12618084/index.pdf

Benson, M., Benson, E., \& Ilson, R. (1986). The BBI combinatory dictionary of English: A guide to word combinations. Amsterdam, The Netherlands: John Benjamins Publishing Company. http://dx.doi.org/10.1075/z.bbi1(1st)

Brashi, A. (2009). Collocability as a problem in L2 production. Reflections in English Language Teaching, 8(1), 21-34.

Conklin, K., \& Schmitt, N. (2007). Formulaic sequences: Are they processed more quickly than nonformulaic language by native and nonnative speakers? Applied Linguistics, 28, 1-18. http://dx.doi.org/10.1093/applin/amm022

Cruse, D. A. (1986). Lexical Semantics. Cambridge: Cambridge University Press.

El-Dakhs, D. (2015). Collocational competence in English Language Teaching: An Overview. Arab World English Journal, 6(1), 68-82.

Fan, M. (2008). An exploratory study of collocational use by ESL students-A task based approach. System, 37(1), 110-123. http://dx.doi.org/10.1016/j.system.2008.06.004

Farrokh, P. (2012). Raising awareness of collocational use by ESL students-A task based approach. System, 37, $110-123$.

Firth, J. (1957). Modes of meaning. In F. Palmer (Ed.), Papers in linguistics (pp. 190-215). London: Oxford University Press.

Hill, J. (2000). Revising Priorities: From Grammatical Failure to Collocational Success. In M. Lewis (Ed.), Teaching Collocation: Further Developments in The Lexical Approach (pp. 49-50). London: Language Teaching Publications.

Honde, L. (2009). Collocations and Teaching: Investigating word combinations in two English textbooks for Norwegian upper secondary school students. Unpublished MA dissertation, University of Bergen, Norway. Retrieved from https://bora.uib.no/bitstream/handle/1956/3824/65352869.pdf?sequence=1

Howarth, P. (1998). Phraseology and Second Language Proficiency. Applied Linguistics, 19(1), 24-44. http://dx.doi.org/10.1093/applin/19.1.24

Jaén, M. M. (2007). A corpus-driven design of a test for assessing the ESL collocational competence of university students. International Journal of English Studies, 7(2), 127-147.

Lewis, M. (1997). Implementing the lexical approach (pp. 34-44). England: Language Teaching Publication.

Lewis, M. (2000). Teaching collocation: Further development in the lexical approach. Hove, Brighton: Language Teaching Publications.

Li, C. (2005). A study of collocational error types in ESL/EFL college learners' writing. Unpublished MA dissertation, Ming, Chuan University, Taiwan. Retrieved from http://www.ethesys.lib.mcu.edu.tw

McCarthy, M. (1990). Vocabulary. Oxford: Oxford University Press.

Milton, J. (2009). Measuring second language vocabulary acquisition. Bristol, England: Multilingual Matters. 
Miqdad, A. A. (2012). The role of mother tongue in reception and production of collocations by English majors at the Palestinian universities. Unpublished MA dissertation, The Islamic University of Gaza, Palestine. Retrieved from http://library.iugaza.edu.ps/thesis/106921.pdf

Nation, P. (2001). Learning vocabulary in another language. Cambridge: Cambridge University Press. http://dx.doi.org/10.1017/CBO9781139524759

Noor, H., \& Adubaib, A. (2011). Strategies used in producing English lexical collocations by Saudi EFL learners. In: 1st International Conference on Foreign Language Teaching and Applied Linguistics (FLTAL'11), 5-7 May 2011, Sarajevo.

Norrish, J. (1994). Language learners and their errors. London: Macmillan Press.

Phoocharoensil, S. (2014). Exploring learners' developing L2 collocational competence. Theory and Practice in Language Studies, 4(12), 2533-2540. http://dx.doi.org/10.4304/tpls.4.12.2533-2540

Schmidt, R. W. (1990). The role of consciousness in second language learning. Applied Linguistics, 11, 129-158. http://dx.doi.org/10.1093/applin/11.2.129

Shammas, N. A. (2013). Collocation in English: Comprehension and use by MA students at Arab universities. International Journal of Humanities and Social Science, 3(9), 107-122.

Shehata, A. (2008). L1 Influence on the reception and production of collocations by advanced ESL/EFL Arabic learners of English. Unpublished MA dissertation, Ohio University, USA. Retrieved from https://etd.ohiolink.edu/rws_etd/document/get/ohiou1218237449/inline

Sinclair, J. (1991). Corpus concordance collocation. Hong Kong: Oxford University Press.

Siyanova, A., \& Schmitt, N. (2008). L2 learner production and processing of collocation: A multi-study perspective. The Canadian Modern Language Review, 64(3), 429-458. http://dx.doi.org/10.3138/cmlr.64.3.429

Torabian, A. H., Maros, M., \& Subakir, M. Y. M. (2014). Lexical collocational knowledge of Iranian undergraduate learners: Implications for receptive and productive performance. Procedia-Social and Behavioral Sciences, 158, 343-350. http://dx.doi.org/10.1016/j.sbspro.2014.12.098

Woolard, G. (2000). Collocation encourages learner independence. In M. Lewis (Ed.), Teaching collocation: Further development in the lexical approach (pp. 28-46). Oxford: Oxford University Press.

Yunus, K. B., \& Awab, S. (2011). Collocational competence among Malaysian undergraduate Law students. Malaysian Journal of ELT Research, 7(1), 151-202.

\section{Appendix A}

Dear Participant,

Thank you for accepting to take this test. The test is only devised for research purposes and will have no effect on your course grades. Your answers will only be used for the purpose of a research study, and will remain absolutely confidential.

Thank you,

The researcher

\section{Exercise (1)}

Fill in each gap with an appropriate VERB. You are provided with the translation equivalent in Arabic.

Note: You can only write ONE word per blank.

Example

Try to dye your hair.

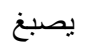

Exercise (2)

Fill in each gap with an appropriate ADJECTIVE. You are provided with the translation equivalent in Arabic.

Note: You can only write ONE word per blank. 
Example

This is a handsome man.

وسيم

\section{Exercise (1)}

Fill in each gap with an appropriate VERB. You are provided with the translation equivalent in Arabic.

Note: You can only write ONE word per blank.

1. You should this advice.

يتجاهل

2. Try to your anger; otherwise, you may fall sick. يعرب عن/ يجاهر

3. I my apology for your consideration.

4. I am trying to the list.

5. Many Saudi cities a beach.

6. I have to the bed.

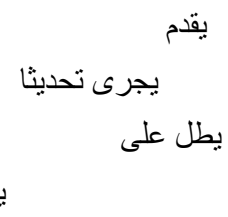

7. The workers are trying to

8. I will my book to my mother. the building.

9. Careful!! You will the car into the front of the bank.<smiles>[AsH][AsH2]</smiles>

10. Do you think she can really a child? يربى

11. The College Dean will

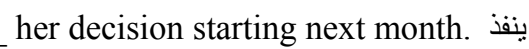

12. It took the doctor no time to the disease.

13. These assignments will great effort.

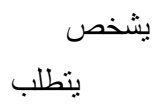

14. Learning to fish is not as easy as many people think. يصطاد

15. The Chairperson is going to the invitation. برفض بأدب

\section{Exercise (2)}

Fill in each gap with an appropriate ADJECTIVE. You are provided with the translation equivalent in Arabic.

Note: You can only write ONE word per blank.

1. The patient suffered from pain.

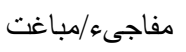

2. Please, stop giving me promises. stories.

3. This lady always tells student.

4. This is a very

5. The country is suffering from the

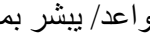

6. I ran across this area of water.

7. The new president is trying to acquire power. مطلقة

8. The students will have to sit for this exam before graduation. شامل

9. The baby has a slightly face.

10. She has beautiful, shiny hair.

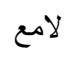

11. Some countries are trying to revive languages.

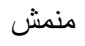

12. The candidate was offered a relatively low salary. أولى/ابتدائى

13. I have made this mistake. بسيط

14. The prime minister paid an extremely visit to a neighboring country. مثرة 15. I find it really difficult to understand the rules of the

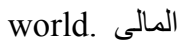




\section{Copyrights}

Copyright for this article is retained by the author(s), with first publication rights granted to the journal.

This is an open-access article distributed under the terms and conditions of the Creative Commons Attribution license (http://creativecommons.org/licenses/by/3.0/). 